\title{
Development of a new high-throughput method to determine the composition of ten monosaccharides including 4-O-methyl glucuronic acid from plant cell walls using ultra-performance liquid chromatography
}

\author{
Shingo Sakamoto ${ }^{1}$, Kouki Yoshida ${ }^{2}$, Satoko Sugihara ${ }^{3}$, Nobutaka Mitsuda ${ }^{1, *}$ \\ ${ }^{1}$ Bioproduction Research Institute, National Institute of Advanced Industrial Science and Technology (AIST), Tsukuba, Ibaraki \\ 305-8566, Japan; ${ }^{2}$ Technology Center, Taisei Corporation, Nase-cho 344-1, Totsuka-ku, Yokohama, Kanagawa 245-0051, \\ Japan; ${ }^{3}$ Technology Center, Nihon Waters K.K., Kita-shinagawa 1-3-12, Shinagawa-ku, Tokyo 140-0001, Japan \\ *E-mail: nobutaka.mitsuda@aist.go.jp Tel: +81-29-861-2641Fax: +81-29-861-3026
}

Received December 26, 2014; accepted January 13, 2015 (Edited by M. Yamaguchi)

\begin{abstract}
Plant cell walls are an important dietary source for livestock, and could be an enormous resource for production of next-generation bioethanol and more valuable materials. Because polysaccharides are major components of plant cell walls, analysis of their composition is important. In this report, we established a high-throughput method to determine the composition of ten monosaccharides from plant cell walls simultaneously using ultra-performance liquid chromatography with $p$-aminobenzoic ethyl ester-labeling technology. Complete separation of a mixture of internal standards, 2-deoxyglucose and 3-O-methyl glucose, and ten monosaccharides, consisting of seven neutral and three acidic sugars including 4-O-methyl-D-glucuronic acid, which are frequently found in plant cell wall polysaccharides, can be obtained within 7 min using this system. Relative standard deviations of retention time and peak area value are lower than $1 \%$. Linearity for broader dynamic ranges $\left(0.02-2000 \mathrm{mgl}^{-1}\right)$, faster analysis and higher sensitivity than other traditional methods, including one that employs widely used high-performance anion exchange chromatography, are achieved. We evaluated this new method by analyzing the composition of cell walls from three model plants (Arabidopsis thaliana, rice and hybrid aspen) and confirmed that the obtained results for most monosaccharides are consistent with those in previous studies. These data suggest that our newly developed system could greatly contribute to the study of plant cell walls, especially research requiring highthroughput analysis.
\end{abstract}

Key words: 4-O-Methyl glucuronic acid, monosaccharide composition, plant cell wall, UPLC.

Plant cell wall polysaccharides are essential compounds for plant bodies, and are an important dietary source for livestock. In addition, it has recently been considered that plant cell walls could be the most abundant terrestrial organic resource for production of next-generation bioethanol and more valuable materials. Plant cell walls contain three major classes of polysaccharides, namely cellulose, hemicellulose and pectin. The composition of polysaccharides varies in each plant species and also in each tissue (Bauer et al. 2006). These polysaccharides are polymers of neutral monosaccharides such as D-glucose (Glc), D-xylose (Xyl), L-fucose (Fuc), L-arabinose (Ara), D-mannose (Man), D-galactose (Gal), L-rhamnose (Rha) and/or acidic monosaccharides such as D-glucuronic acid (GlcA), D-galacturonic acid (GalA), and 4-O-methyl-D- glucuronic acid (4-m-GlcA). Neutral monosaccharides are components of cellulose, and the backbones and/or side chains of hemicelluloses, while acidic monosaccharides are components of the pectin backbone or side chains of heteroxylan (Albersheim et al. 2010). Recently, not only cellulose (Somerville 2003) and the backbone of hemicelluloses (Brown et al. 2009; Jensen et al. 2014), but also the modification of GalA residues in pectin of primary cell wall (Hongo et al. 2012) and GlcA/4-m-GlcA side chains of heteroxylan of secondary cell wall (Lee et al. 2012) have been demonstrated to be essential for normal plant growth. Regarding saccharification of plant biomass, the arabinofuranose side chains promote hydrolysis of heteroxylan by some xylanases (Shallom and Shoham 2003). In addition, the

Abbreviations: ABEE, $p$-aminobenzoic ethyl ester; AIR, alcohol insoluble residue; Ara, L-arabinose; Fuc, L-fucose; GC, gas liquid chromatography; GC-MS, gas liquid chromatography-mass spectometry; 2-d-Glc, 2-deoxy-glucose; Gal, D-galactose; GalA, D-galacturonic acid; HPAEC, highperformance anion exchange chromatography; HPLC, high-performance liquid chromatography; Glc, D-glucose; GlcA, D-glucuronic acid; Man, Dmannose; 3-m-Glc, 3-O-methyl glucose; 4-m-GlcA, 4-O-methyl-D-glucuronic acid; PA, peak area; PAD, pulsed amperometric detection; RSD, relative standard deviation; TFA, trifluoroacetic acid; UPLC, ultra-performance liquid chromatography; Rha, L-rhamnose; Xyl, D-xylose.

This article can be found at http://www.jspcmb.jp/

Published online February 20, 2015 
reduction of the degree of 4-O-methylation to GlcA on the glucuronoxylan of Arabidopsis mutants was found to increase the release of Xyl during hydrothermal pretreatment of plant cell wall (Urbanowicz et al. 2012). These reports suggest that the profiling of neutral and acidic monosaccharides from total plant cell walls is important for characterizing plant cell wall in the context of growth properties and/or for achieving improved conversion efficiency of the cell wall to ethanol.

To this end, chromatographic analysis is the main technique; gas liquid chromatography (GC) and GCmass spectrometry (GC-MS) analyses are widely employed to analyze acid hydrolysates of polysaccharides and provide accurate and reproducible data of the composition of neutral and acidic monosaccharides in plant cell walls (Albersheim et al. 1967; Blakeney et al. 1983; Doco et al. 2001; Hoebler et al. 1989). However, this method based on the GC system requires timeconsuming derivatization of monosaccharides to alditol acetates or trimethylsilyl ethers (McNeil et al. 1982; Pettolino 2012). On the other hand, high-performance anion exchange chromatography (HPAEC) with pulsed amperometric detection (PAD) had been developed as a method to improve the sensitivity of monosaccharide detection without derivatization and is widely used for the plant cell wall analysis (De Ruiter et al. 1992). A recent study improved the HPAEC-PAD method to quantify two acidic monosaccharides in addition to seven neutral monosaccharides taking only $60 \mathrm{~min}$ of analytic time with high resolution (Nagel et al. 2014). However this advanced method has different linearity range for some monosaccharides, such as that for GalA $\left(1.7-128 \mu \mathrm{moll}^{-1}\right)$ is different from those of other sugars $\left(0.28-30.3 \mu \mathrm{moll}^{-1}\right.$, Nagel et al. 2014). In addition, Chong et al. (2013) has reported that the PAD response of $4-\mathrm{m}-\mathrm{GlcA}$ is one-third from that of GlcA. These differences necessitate several injections at different concentration levels for the comprehensive quantification of monosaccharides.

A method for high-performance liquid chromatographic (HPLC) analysis of monosaccharides with pre-column derivatization to produce a fluorophore is also commonly employed (Takemoto et al. 1985), which involves $p$-aminobenzoic ethyl ester (ABEE) derivatization of carbohydrates (Matsuura and Imaoka 1988). In the ABEE-labeling method, monosaccharides are derivatized for $1 \mathrm{~h}$ and excess reagents are easily removed by chloroform (Yasuno et al. 1999). In addition, the labeling efficiency of ABEE is mostly comparable for a broad range of neutral and acidic saccharide species and ABEE-labeled monosaccharides are efficiently separated in HPLC systems using borate buffer as an eluent, resulting in excellent resolution and wide linearity of $1-1000 \mathrm{pmol}$ at a chromatographic injection for each monosaccharide (Yasuno et al. 1999). This suggests that the ABEE-labeling procedure is one of the most suitable methods for simultaneous determination of neutral and acidic monosaccharides from plant cell walls. However, the total run time of ABEE-labeled monosaccharide separation with HPLC is ca. $75 \mathrm{~min}$ for each sample analysis and therefore longer than the HPAEC-PAD method (Nagel et al. 2014). Recently, Kumagai et al. (2012) applied the ultra performance liquid chromatography (UPLC) system, which is a relatively new technique giving new possibilities in liquid chromatography by shortening run time, improving peak resolution, and sensitivity (Swartz 2005), to analyze the composition of trifluoroacetic acid (TFA)-hydrolyzable polysaccharides from Hinoki cypress (Chamaecyparis obtusa) slurry. However, chromatographic conditions such as the running time, peak resolutions, and the linearity ranges of each monosaccharide, which are important to evaluate the accuracy of their conditions, remained to be validated. In addition, the amount of 4-m-GlcA in their material was not intended to be analyzed even though Hinoki xylan is enriched with 4-m-GlcA (Ishii et al. 2010). The internal standard which is used for the calibration and estimation of the injection volume and the loss of monosaccharide during the acid hydrolysis (McNeil et al. 1982; Pettolino et al. 2012), also remained to be established (Kumagai et al. 2012). Therefore further development of the chromatographic conditions for UPLC with ABEE-labeling system is still needed for the rapid, accurate and comprehensive quantification of the monosaccharide composition of the plant cell wall including 4-m-GlcA using internal standard.

In this study, we established a system to rapidly analyze major 10 plant cell wall monosaccharides by combining UPLC with the ABEE-labeling technique. We also demonstrated that 2-deoxy-glucose (2-d-Glc) and 3-O-methyl glucose (3-m-Glc) can be used as the internal standard in this system. A total run time is shortened to $6.5 \mathrm{~min}$, sensitivity is increased to $2-5 \mathrm{fmol}$ per injection and the linearity range is broadened to $0.02-2000 \mu \mathrm{g} \mathrm{ml}^{-1}$. We applied this simultaneous monosaccharide determination method to the cell wall samples of inflorescence stem of Arabidopsis thaliana, culm of rice, and poplar wood for the method evaluation. We verified that this method allows us a rapid and sensitive determination of 10 cell-wall-composing sugars including $4-\mathrm{m}-\mathrm{GlcA}$ in actual biomass samples in reasonable ranges, indicating that this new highthroughput chromatographic method could be an innovative tool for studying plant cell wall composition.

\section{Materials and methods}

\section{Chemicals}

The standard monosaccharides, Gal, Man, Ara, Xyl, Fuc, and Rha were purchased from Kanto Chemical Inc. (Japan), GlcA, 
GalA, and 2-D-Glc were obtained from Sigma-Aldrich Inc. (USA), and Glc and 3-m-Glc was sourced from Wako Pure Chemical Industries, Ltd. (Japan). An ABEE-labeling kit was purchased from J-Oil mills Inc. (Japan). 4-m-GlcA purified from the sap of a lac tree (Kuroyama et al. 2001; Nakamura et al. 1984) was kindly gifted from Prof. Y. Tsumuraya (Saitama University, Japan). Synthetic $4-\mathrm{m}-\mathrm{GlcA}$ is also commercially available from Toronto Research Chemicals Inc. (www.trccanada.com, Cat. \#: M308350).

\section{Plant materials}

A. thaliana ecotype Columbia- 0 were grown in soil at $22^{\circ} \mathrm{C}$ under a $16 \mathrm{~h}$ day $\left(60-70 \mu \mathrm{mol} \cdot \mathrm{m}^{-2} \cdot \mathrm{s}^{-1}\right) / 8 \mathrm{~h}$ night cycle after 3 weeks of germination on $1 / 2$ Murashige and skoog medium. Regenerated rice plants (Oryzae sativa cv. Nippon-bare) from seed callus (Hiei et al. 1994) were grown in soil for 8 months at $28^{\circ} \mathrm{C}$ under a $13 \mathrm{~h}$ day $\left(130-150 \mu \mathrm{mol} \cdot \mathrm{m}^{-2} \cdot \mathrm{s}^{-1}\right) / 11 \mathrm{~h}$ night cycle in a phytotron. Rooted cuttings of hybrid aspen (Populus tremula $\times$ Populus tremuloides) were grown in the greenhouse at ambient temperature under natural light.

\section{Preparation of cell wall residue}

The inflorescence stem of 2-month-old A. thaliana, the culms of 8-month-old O. sativa, was cut into $1 \mathrm{~cm}$-segments and fixed with methanol in a $50 \mathrm{ml}$-Pyrex glass tube with a screw cap (Asahi Glass Inc., Japan). The fixed samples were treated with methanol twice at $80^{\circ} \mathrm{C}$ for $10 \mathrm{~min}$, twice with acetone at $70^{\circ} \mathrm{C}$ for $5 \mathrm{~min}$, and twice with methanol/chloroform $(1: 1, \mathrm{v} / \mathrm{v})$ at $70^{\circ} \mathrm{C}$ for $5 \mathrm{~min}$ and then dried at $65^{\circ} \mathrm{C}$ for $18 \mathrm{~h}$. The dried tissue segments were powdered with a stainless steel bead ( $6 \mathrm{~mm}$, Biomedical Science, Japan) and three zirconia beads ( $3 \mathrm{~mm}$, Nikkato Corp., Japan) using a Shake Master NEO (Biomedical Science Inc., Japan). In case of poplar, xylem tissues were collected from 1-2 years old twigs and then ground into fine powder. The starch in resulting powder of A. thaliana, $O$. sativa, and poplar was degraded with $\alpha$-amylase solution and de-starched residue was prepared as previously described (Sakamoto and Mitsuda 2014). The de-starched residue was designated as alcohol-insoluble residue (AIR).

\section{Sulfuric acid hydrolysis of the cell wall}

The AIR was hydrolyzed by the two-step hydrolysis method based on NREL protocol (Sluiter et al. 2008) with slight modification as previously described (Sakamoto and Mitsuda 2014). As a recovery standard, we prepared the authentic monosaccharide-standards including 7 neutral monosaccharides and 3 acidic monosaccharides $(20 \mu \mathrm{g}$ each in a tube, see Figure 1) in a 2 ml-Eppendorf safe-lock microtube and added $1.45 \mathrm{ml}$ of $4 \%$ sulfuric acid. After addition of $10 \mu \mathrm{l}$ of $3-\mathrm{m}$-Glc solution $\left(1 \mathrm{mg} \mathrm{ml}^{-1}\right)$ as an internal standard, the resulting suspension was autoclaved at $121^{\circ} \mathrm{C}$ for $1 \mathrm{~h}$ and cooled at room temperature. The hydrolysate was neutralized and adjusted to around $\mathrm{pH} 5.0$ with calcium carbonate powder. The supernatant of neutralized hydrolysate was used for ABEE-labeling.

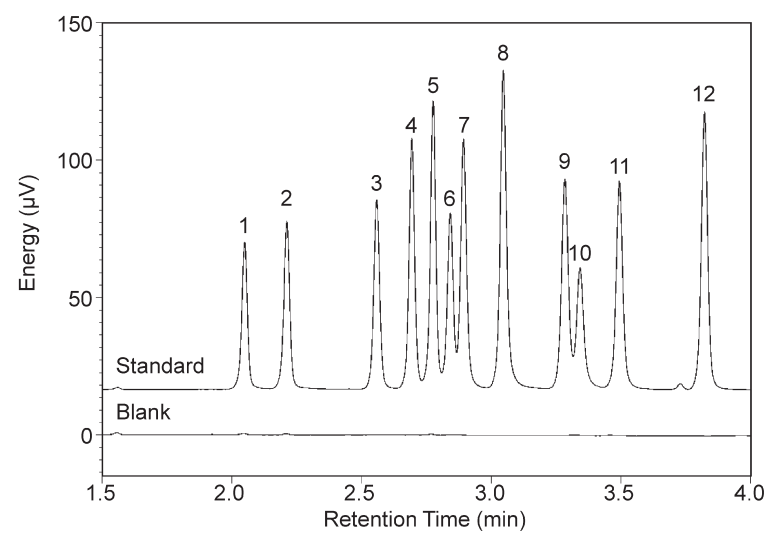

Figure 1. UPLC chromatogram of monosaccharides labeled with ABEE. A monosaccharide mixture $\left(20 \mu \mathrm{g} \mathrm{ml}^{-1}\right.$ of each, Standard $)$ and ultrapure water (Blank) was reacted with ABEE regent and $2 \mu \mathrm{l}$ of reacted solution containing $0.89 \mathrm{ng}$ of ABEE-labeled monosaccharides was injected for chromatographic analysis. Peak assignment: 1, GlcA; 2, GalA; 3, Gal; 4, Man; 5, Glc; 6, 4-m-GlcA; 7, Ara; 8, Xyl; 9, Fuc; 10, Rha; 11,2-d-Glc; 12, 3-m-Glc.

\section{Preparation of ABEE-labeled monosaccharides}

The acidic and neutral monosaccharides were labeled with an ABEE labeling kit (J-Oil mills Inc., Japan) based on the method of Yasuno et al. (1999). Twenty-microliter of ABEE reagent, which was prepared as described in Yasuno et al. (1999), was added to $5 \mu \mathrm{l}$ of the neutralized hydrolysates in a $1.5 \mathrm{ml}$-microtube. The mixture was heated at $80^{\circ} \mathrm{C}$ for $1 \mathrm{~h}$ and then cooled to room temperature. Two hundred-microliter of distilled water and $200 \mu \mathrm{l}$ of chloroform were added. After vigorous vortexing, the mixture was centrifuged at $20,000 \times g$ for $1 \mathrm{~min}$ at $25^{\circ} \mathrm{C}$, and then the upper aqueous phase was collected. This aqueous phase containing ABEE-labeled monosaccharides was filtrated with syringe filter unit (MillexLG $0.2 \mu \mathrm{m}$ pore, Millipore Inc., USA) and the resulting solution was analyzed with UPLC system.

\section{UPLC conditions}

The chromatographic separation and detection of monosaccharides labeled with ABEE was performed using an ACQUITY UPLC H-Class system (Waters Inc., USA) equipped with ACQUITY UPLC BEH C18 column $(100 \mathrm{~mm} \times 2.0 \mathrm{~mm}$, id, $1.7 \mu \mathrm{m}$ particle size, Waters Inc.) and fluorescence detector (ACQUITY UPLC FLR Detector, Waters Inc.). The eluent A was $200 \mathrm{mM}$ potassium borate buffer ( $\mathrm{pH}$ 8.9). The eluent $\mathrm{B}$ was $100 \%$ acetonitrile. The column was equilibrated with the mixture of $97 \%(\mathrm{v} / \mathrm{v})$ eluent $A$ and $3 \%(\mathrm{v} / \mathrm{v})$ eluent $\mathrm{B}$ at a flow rate of $0.7 \mathrm{ml} \mathrm{min}^{-1}$. The elution was started with a linear gradient of eluent B from 3 to $21 \%$ at a flow rate of $0.7 \mathrm{ml} \mathrm{min}^{-1}$ for $4.0 \mathrm{~min}$. The elusion program including washing and regeneration of the column was shown in gradient profile 4 in Supplementary Table S1. The temperature of column and autosampler was maintained at $50^{\circ} \mathrm{C}$ and $10^{\circ} \mathrm{C}$ respectively. The ABEE-labeled monosaccharides were detected with $305 \mathrm{~nm}$ of emission and $360 \mathrm{~nm}$ of excitation using fluorescence detector. The injection volume of all samples was $2 \mu \mathrm{l}$. 
Table 1. Comparison of assay conditions between a previous study*1 and this study.

\begin{tabular}{|c|c|c|}
\hline & Kumagai et al. (2012) & This study \\
\hline Eluent method & Isocratic & One step gradient \\
\hline Detector & UV & Fluorescence \\
\hline Column length (mm) & 150 & 100 \\
\hline Initiate buffer composition & $\mathrm{A}^{* 2}$ containing $10 \% \mathrm{~B}^{* 3}$ & Mixture of $97 \% \mathrm{~A}$ and $3 \% \mathrm{~B}$ \\
\hline Flow rate $(\mathrm{ml} / \mathrm{min})$ & 0.3 & 0.7 \\
\hline Column temperature $\left({ }^{\circ} \mathrm{C}\right)$ & 30 & 50 \\
\hline
\end{tabular}

${ }^{* 1}$ Kumagai et al. (2012), ${ }^{* 2} \mathrm{~A}, 200 \mathrm{mM}$ potassium borate $(\mathrm{pH} 8.9),{ }^{* 3} \mathrm{~B}, 100 \%$ acetonitrile.

\section{Determination of peak resolution $\left(R_{P 1, P 2}\right)$}

The resolution $\left(\mathrm{R}_{\mathrm{P} 1, \mathrm{P} 2}\right.$; Equation 1$)$ between two adjacent peaks (P1 and P2) was deduced from the retention times of the two analytes $\left(\mathrm{RT}_{\mathrm{P} 1}, \mathrm{RT}_{\mathrm{P} 2}\right)$ and the baseline widths $\left(\mathrm{W}_{\mathrm{P} 1}\right.$ and $\left.\mathrm{W}_{\mathrm{P} 2}\right)$ resulting from the tangents of the inflection points of each peak (Nagel et al. 2014).

$$
\mathrm{R}_{\mathrm{P} 1, \mathrm{P} 2}=2\left(\mathrm{RT}_{\mathrm{P} 2}-\mathrm{RT}_{\mathrm{P} 1}\right) /\left(\mathrm{W}_{\mathrm{P} 2}+\mathrm{W}_{\mathrm{P} 1}\right)
$$

\section{Results and discussion}

\section{Assay condition to separate twelve monosaccharides by UPLC was established}

Based on established methodologies for the ABEE labeling of monosaccharides (Kwon and Kim 1993; Yasuno et al. 1997, 1999), Kumagai et al. (2012) determined the monosaccharide composition of slurry of Chamaecyparis obtusa (Hinoki cypress) wood after the method transfer from HPLC to UPLC. However, (1) the established column performance such as specificity and stability remained to be validated. (2) 4-m-GlcA, which is present in major side chains of heteroxylan in secondary cell wall of eudicot, was not intended to be analyzed and (3) the internal standard correction was not applied. Because of these reasons, evaluation of the method transfer from HPLC to UPLC is still needed in addition to establishment of the condition to separate 4-m-GlcA, two other acidic monosaccharides, seven neutral monosaccharides and two modified monosaccharides (2-d-Glc or 3-m-Glc) which are not usually detected in the plant cell wall (as the potential internal standards). Using the same chromatographic conditions as those reported previously except for employing a shorter column in this study to shorten the total run time, all compounds were eluted within 10 min of injection in their isocratic elution with $10 \%$ acetonitrile (Supplementary Figure S1, isocratic 1). It was found that Glc co-eluted with $4-\mathrm{m}-\mathrm{GlcA}$ at $5.02 \mathrm{~min}$ under these conditions, although the separation of other monosaccharides was mostly acceptable (Supplementary Figure S1, isocratic 1). In addition, the total run time including wash and regeneration of the column was $25 \mathrm{~min}$. Although this time frame is better than those of GC or HPLC methods, further shortening is desirable. Therefore, we needed to develop the different chromatographic conditions to separate all of the major monosaccharides from the plant cell wall and to shorten run time. Through many trial-and-error procedures, as described in detail in Supplementary Text, we finally established appropriate assay conditions that allowed rapid separation of all the monosaccharides (Figure 1). Under these conditions, the elution-program, the mobile phase, flow rate and column temperature were entirely changed from those of the reported method by Kumagai et al. (2012) (Table 1). Total analysis time was shortened to $6.5 \mathrm{~min}$, including column washing and re-equilibration (Gradient profile 4 in Supplementary Table S1), and 4-m-GlcA was able to be detected simultaneously with the other monosaccharides and two internal standard candidates.

\section{The established method has improved linearity and sensitivity}

The reproducibility of the developed method was assessed by carrying out 12 independent injections of a mixture of twelve authentic monosaccharides. As listed in Tables 2 and 3, the relative standard deviation (RSD) values of retention time (RT) and peak area (PA) were less than $1 \%$ for all examined monosaccharides. These data indicate that the established system has a sufficient robustness for repeated analyses of chromatographic injection.

Supplementary Table S2 shows that the peak resolution values between each pair of two neighboring monosaccharides in the chromatograph except for " $4-\mathrm{m}-\mathrm{GlcA} / \mathrm{Ara}(0.80 \pm 0.01)$ " and "Fuc/Rha $(0.82 \pm 0.01)$ " were between $0.99 \pm 0.01$ and $2.25 \pm 0.05$, when $0.89 \mathrm{ng} / 2 \mu \mathrm{l}$ of sample was injected. This indicates that the separations of all tested monosaccharides were acceptable. Reduction of the injected sample amount from $0.89 \mathrm{ng} / 2 \mu \mathrm{l}$ to $0.05 \mathrm{ng} / 2 \mu \mathrm{l}$ markedly increased the peak resolution values for five pairs of monosaccharides without affecting those of the other four pairs of monosaccharides (Supplementary Table S3).

We also investigated the relationship between peak area and the concentration of monosaccharide labeled with $\mathrm{ABEE}$ to estimate the linearity range for the determination of monosaccharide concentration. As shown in Figure 2, the linearity of GlcA and 4-m-GlcA, for example, in our established method ranged from 
Table 2. Reproducibility of retention time of ABEE-labeled monosaccharides using the established separation conditions shown in gradient profile 4 of Table S1.

\begin{tabular}{lc}
\hline Monosaccharide* & Retention time (min) \\
\cline { 2 - 2 } & AVE \pm SD $(\operatorname{RSD} \%, n=12)$ \\
\hline GlcA & $2.04 \pm 0.004(0.18)$ \\
GalA & $2.21 \pm 0.003(0.16)$ \\
Man & $2.55 \pm 0.004(0.14)$ \\
Glc & $2.69 \pm 0.004(0.14)$ \\
4-m-GlcA & $2.77 \pm 0.004(0.15)$ \\
Ara & $2.83 \pm 0.004(0.15)$ \\
Xyl & $2.89 \pm 0.004(0.13)$ \\
Fuc & $3.04 \pm 0.004(0.13)$ \\
Rha & $3.28 \pm 0.004(0.12)$ \\
2-d-Glc & $3.34 \pm 0.004(0.11)$ \\
3-m-Glc & $3.49 \pm 0.004(0.10)$ \\
\hline
\end{tabular}

*ABEE-labeled monosaccharide mixture ( $0.89 \mathrm{ng}$ of each monosaccharide per chromatographic injection) was injected.

Table 3. Detected area value of various monosaccharides using the established separation conditions shown in gradient profile 4 of Table S1.

\begin{tabular}{lc}
\hline \multirow{2}{*}{ Monosaccharide* } & Peak area value $\left(\mu \mathrm{V} \cdot \mathrm{s}^{-1} \times 10^{4}\right)$ \\
\cline { 2 - 2 } GlcA & AVE $\pm \operatorname{SD}(\operatorname{RSD} \%, n=12)$ \\
GalA & $83 \pm 0.61(0.74)$ \\
Gal & $99 \pm 0.45(0.45)$ \\
Man & $113 \pm 0.32(0.28)$ \\
Glc & $135 \pm 0.39(0.29)$ \\
4-m-GlcA & $142 \pm 0.48(0.34)$ \\
Ara & $75 \pm 0.66(0.88)$ \\
Xyl & $121 \pm 1.08(0.89)$ \\
Fuc & $207 \pm 0.76(0.37)$ \\
Rha & $117 \pm 0.43(0.37)$ \\
2-d-Glc & $58 \pm 0.33(0.54)$ \\
3-m-Glc & $140 \pm 0.56(0.40)$ \\
\end{tabular}

*ABEE-labeled monosaccharide mixture $(0.89 \mathrm{ng} / 2 \mu \mathrm{l}$ of each monosaccharide) was injected.

0.02 to $2000 \mu \mathrm{g} \mathrm{ml}^{-1}$ (approximately $0.004-400$ pmol per chromatographic injection) with a correlation coefficient $r^{2}$ value of 0.99 (Supplementary Table S4). This is much better than the previous report in which the detection linearity of detected monosaccharides was $1-1000 \mathrm{pmol}$ per chromatographic injection in HPLC (Yasuno et al. 1999). Our results indicate that the reestablished UPLC method shows markedly improved linearity range (up to 100 fold) and sensitivity (up to 250 fold) for the determination of all examined monosaccharides compared with those of HPLC.

\section{Application of the established method to three different types of plant cell walls produced reasonable results}

To evaluate the analytical procedure with the UPLC system in actual plant cell wall samples, we quantified the monosaccharide contents in sulfuric acid-hydrolysate

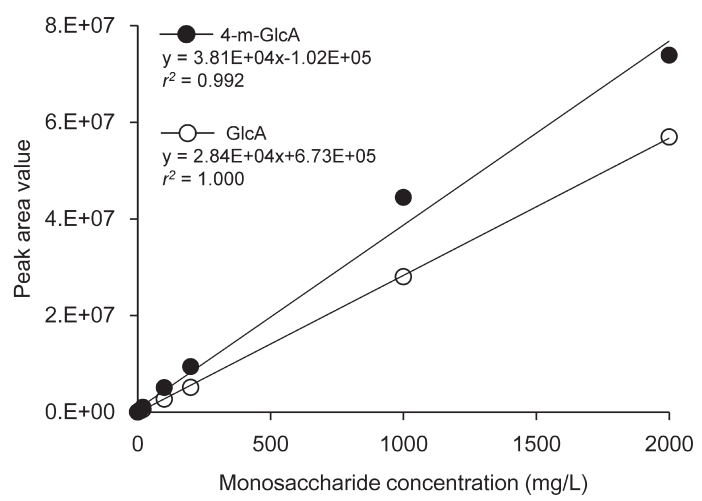

Figure 2. Relationship between area value and monosaccharide concentration of GlcA and 4-m-GlcA. Each concentration (0.02$2000 \mathrm{mg} / \mathrm{l}$ ) of ABEE-labeled monosaccharide was prepared by dilution. The peak area and concentration of 4-m-GlcA (filled circles) and GlcA (open circles) are plotted.

of three types of plant cell walls; namely, inflorescence stem of A. thaliana, culm of rice, and woody tissues of poplar stem. According to the recovery rate of sulfuric acid hydrolysis described in Supplementary text, 3-m-Glc is resistant to sulfuric acid hydrolysis, while 2 -d-Glc is intensely degraded (Supplementary Table S5). Therefore 3-m-Glc was used for internal standard in sulfuric acid hydrolysate in this application.

As shown in Figure 3A, the chromatogram of cell wall hydrolysate revealed the 2 major peaks (peak No. 5 and 8 ) and 9 minor but significant peaks (peak No. 1 to 4,6 to 10 , and 12 as an internal standard, See Figure $3 \mathrm{~A}-\mathrm{D}$ ), whose elution times were identical to those of monosaccharide standards, in all tested plant tissues. These two major monosaccharides were Glc and Xyl, respectively and other minor monosaccharides are three uronic acids (GalA, GlcA, and 4-m-GlcA) and five neutral sugars (Ara, Fuc, Gal, Man and Rha). The chromatogram also revealed that some unknown peaks eluted between GlcA and GalA around the elution time of $2.2 \mathrm{~min}$ (Figure $3 \mathrm{~A}, \mathrm{~B}$ ). These unknown peaks might be products from incomplete hydrolysis with sulfuric acid, such as substance with aldobiuronic acid structures presumably from arabinogalactan protein (Yates et al. 1996) or glucuronoxylans, which are relatively resistant to acid hydrolysis (Chong et al. 2013; Vignon and Gey 1998).

We calculated the monosaccharide contents in the cell wall of tested plants with the recovery rate (Supplementary Table S6) and compared our data with the previous reports in same or similar plant species (Figure 4). Most monosaccharide contents quantified in this study were in the range of previous studies, except for Rha in A. thaliana and GalA in poplar species (Figure 4). Rha content in A. thaliana cell wall in this study $\left(20.5 \pm 1.5 \mu \mathrm{g} \mathrm{m}^{-1}\right.$ AIR) was ca. 1.5 to 3 times 

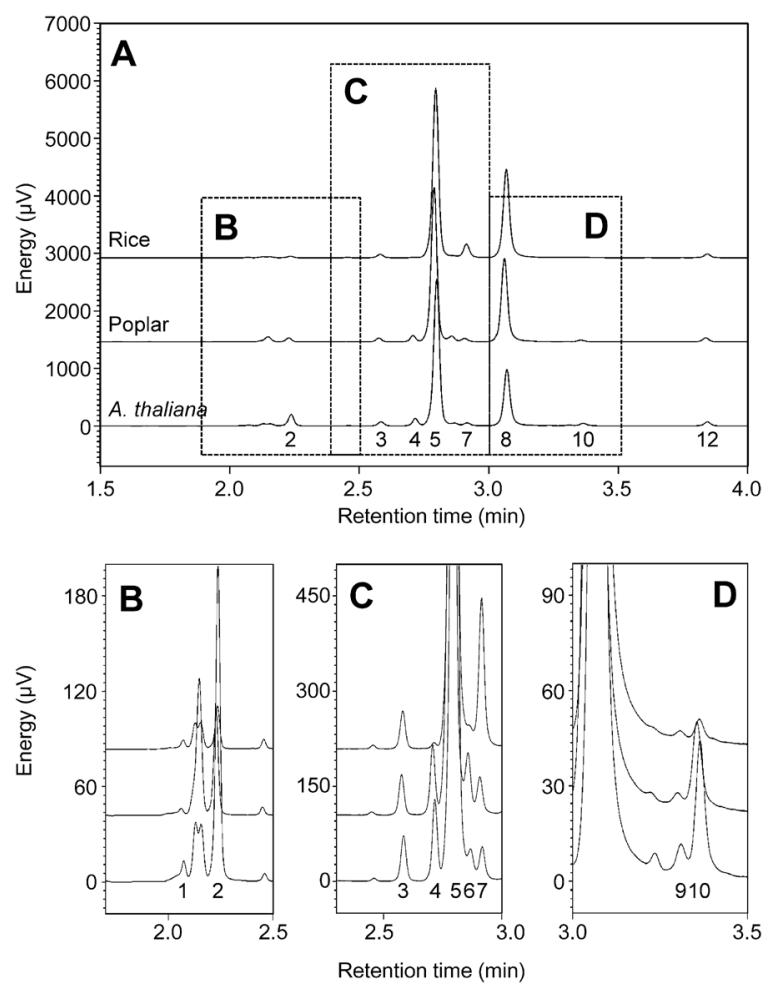

Figure 3. UPLC chromatogram of plant cell wall hydrolyzed by sulfuric acid. Monosaccharide profiles of cell walls from three plants A. thaliana, rice culm, and poplar stem are shown. The hydrolysates of cell wall samples were neutralized using calcium carbonate and then the supernatant was labeled with ABEE. Labeled monosaccharide in hydrolysate $(2 \mu \mathrm{l})$ was injected for chromatographic analysis. Peak assignments are shown in Figure 1. A: Total chromatogram of cell wall acid hydrolysates from three plants. B to D: Expanded chromatograms from (A) to show minor but significantly detected peaks of monosaccharides.

higher than the previous studies, but relatively close to the data (14.4 and $17.3 \mu \mathrm{g} \mathrm{mg}^{-1}$ AIR) determined by the combination of the two step-hydrolysis with sulfuric acids and the quantification with GC (Lee et al. 2011b, 2012), while the data determined with HPEAC-PAD system (9.6 and $10.6 \mu \mathrm{g} \mathrm{mg}^{-1}$ AIR, Eudes et al. 2012; Iwase et al. 2009) and the data determined by the combination of one-step hydrolysis and GC $\left(6.72 \mu \mathrm{g} \mathrm{mg}^{-1}\right.$ AIR, Persson et al. 2007) were low. Therefore higher content of Rha in A. thaliana in this study might be caused by the difference of peak resolution of quantification apparatus (HPAEC or GC) and hydrolysis condition between our study (two-step) and the previous studies.

In case of $4-\mathrm{m}-\mathrm{GlcA}$ in rice and Fuc in poplar, few report showed the quantification data though we detected significant peaks in the all tested plant species (peak No. 6 in Figure 3C, No. 9 in Figure 3D, Supplementary Table S6). Leplé et al. (2007) used Fuc as an internal standard for HPAEC analysis of the monosaccharide composition in poplar cell wall, indicating that the Fuc in poplar wood sample is below
A
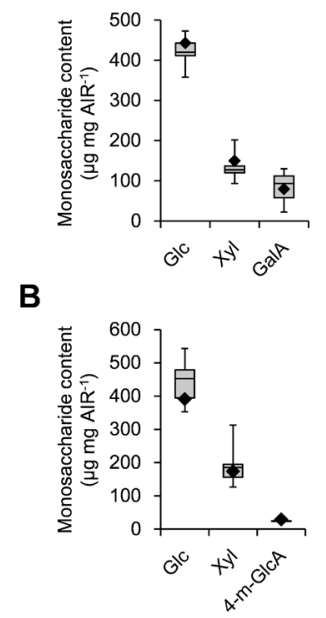

B

C

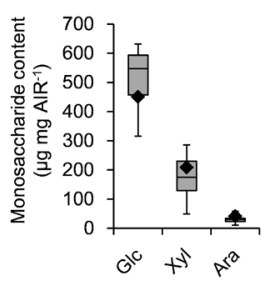

D

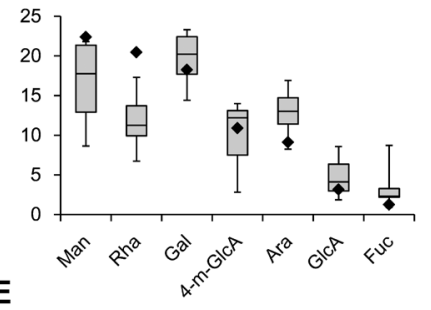

E

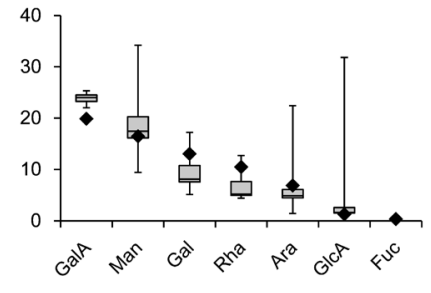

$\mathbf{F}$

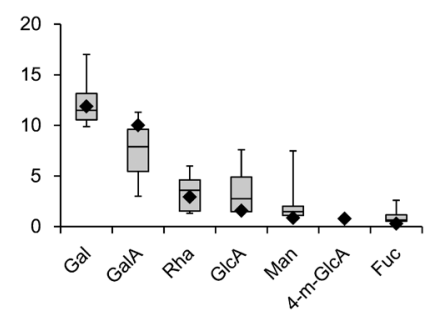

Figure 4. Comparison of monosaccharide compositions of cell walls from stem/culm in Arabidopsis, poplar, and rice between this study and previous studies. Contents of three major and seven minor monosaccharides of cell walls were determined for Arabidopsis inflorescence stems (A, D), poplar woody stems (B, E), and rice culms (C, F). The positions of monosaccharides are arranged in order of higher amounts determined in this study. The filled diamonds indicate the monosaccharide contents determined in this study $(n=4$ for Arabidopsis and rice, $n=2$ for poplar). Gray boxplots represent a range of values in previous studies; seven studies of Arabidopsis, six studies of poplar species, and six studies of rice, respectively (See supplementary Table S9 in detail). Horizontal bar in the gray box indicates the median of the reported values. Upper and lower hinges of gray box indicate $75 \%$ - and $25 \%$-ranges of reported values, respectively. The upper and lower extreme bars of box plot indicate maximum (upper) and minimum (lower) of reported values, respectively.

the detection limit of HPEAC-PAD system. Hence, our improvement of the sensitivity may contribute to more detailed quantification of the monosaccharides in poplar wood sample.

Our analysis of monosaccharide composition of plant cell walls clearly revealed the difference between A. thaliana, poplar, and rice as reviewed previously (Albersheim et al. 2010; Carpita and Gibeaut 1993). The contents of Glc, Xyl and GalA were higher than those of other monosaccharides in Arabidopsis (Figure 4, Supplementary Table S6), which is consistent with the previous report that cellulose, xyloglucan, xylan and polygalacturonic acid are major cell wall components in eudicot plants (Zablackis et al. 1995). The contents of Glc, Xyl, and 4-m-GlcA were higher than those of other monosaccharides in poplar cell wall, which is also consistent with the previous review in which cellulose 
Table 4. Comparison of chromatographic analyses used to determine monosaccharide composition.

\begin{tabular}{lcccl}
\hline \multicolumn{1}{c}{ Procedure } & Derivatization $(\mathrm{h})$ & Analysis $(\mathrm{min} / \mathrm{run})$ & Linearity $\left(\mathrm{mgl}^{-1}\right)$ & \multicolumn{1}{c}{ Reference } \\
\hline UPLC-ABEE & 1 & 6.5 & $0.02-2000$ & This study \\
HPLC-ABEE & 1 & 75 & $4.5-4500^{* 1}$ & Yasuno et al. (1999) \\
HPEAC-PAD & None & 60 & $0.05-5.5^{* 2}$ & Nagel et al. (2014) \\
& & & $3.3-24.9^{* 3}$ & Blakeney et al. (1983) \\
GC-FID & 3 & 30 & $0.1-150^{* 4}$ & Jones and Albersheim (1972) \\
& 3 & 30 & $0.3-3.0^{* 5}$ & Guadalupe et al. (2012) \\
GC-MS & 17 & 65 & $0.6-1500 \mu \mathrm{g}^{* 6}$ & \\
\end{tabular}

${ }^{* 1}$ Concentration was calculated from the linearity range shown as $1-1000$ pmol. ${ }^{* 2}$ Neutral monosaccharide and GlcA, ${ }^{* 3}$ : GalA, ${ }^{* 4}$ Neutral monosaccharides from Jones and Albersheim (1972), ${ }^{* 5}$ GlcA and GalA, ${ }^{* 6}$ Monosaccharides except GlcA, ${ }^{* 7}$ GlcA.

and 4-O-methyl-glucurono xylan are described as major components of dicotyledonous woody plants (Sannigrahi et al. 2010). In case of rice cell wall, contents of Glc, $\mathrm{Xyl}$ and Ara were relatively high, while the content of GalA was lowest among three tested species, which well describes the characteristics of Poaceae cell wall; namely, cellulose, mixed linkage-glucan, and arabinoxylan are major components but polygalacturonic acid is minor (Smith and Harris, 1999).

In terms of GlcA methylation, we found that $95 \%$, $77 \%$, and $30 \%$ of GlcA were methylated in poplar, Arabidopsis, and rice cell walls, respectively (calculated from Supplementary Table S6). According to previous studies, almost all and $60 \%$ of GlcA were described to be methylated in poplar (Lee et al. 2011a, 2012) and Arabidopsis (Lee et al. 2012; Zhong et al. 2005), respectively, and therefore our data is consistent with these previous studies. By contrast in case of rice, it is difficult to evaluate this value because few report succeeded to quantify the amount of 4-m-GlcA in rice as mentioned above.

\section{Conclusion}

The UPLC system established here greatly improves the throughput and quantification range of seven neutral and three acidic monosaccharides including 4-m-GlcA from plant cell walls in addition to $3-\mathrm{m}$-Glc as an internal standard. As listed in Table 4, we were able to shorten the total time for the chromatographic analysis of monosaccharides to $6.5 \mathrm{~min}$ and improved both the linearity range and detection limit, with a 100 -fold increase of the linearity range and 200-500-fold increase of the detection limit compared to those of the HPLCABEE method. Furthermore, the developed method gives mostly comparable data for the monosaccharide compositions of plant cell walls with those of previous studies using GC or HPAEC-PAD systems. We believe this new UPLC system will greatly contribute to the study of plant cell walls and assist development of production of bioethanol and other valuable materials.

\section{Funding}

This work was supported by the Advanced Low Carbon Technology Research and Development Program (ALCA) by Japan Science and Technology Agency (JST) (to N. M.).

\section{Acknowledgements}

The authors appreciate Prof. Yoichi Tsumuraya (Saitama University, Japan) for kindly giving us 4-m-GlcA, Dr. Toru Taniguchi and Dr. Naoki Takata (Forestry and Forest Products Research Instutite, Japan) for providing poplar sample, and Mr. Mitsuhiro Tamura and Mr. Kiyotaka Yamashita (Nihon Waters K. K., Japan) for precious suggestions about UPLC operation. The authors also thank Ms. Aeni Hosaka (AIST), Ms. Yoshimi Sugimoto (AIST), and Ms. Miyo Yamada (AIST) for their skillful technical assistance.

\section{References}

Albersheim P, Darvill A, Roberts K, Sederoff R, Staehelin A (2010) Plant cell walls: from chemistry to biology. Garland Science, New York, pp 43-118

Albersheim P, Nevins DJ, English PD, Karr A (1967) A method for the analysis of sugars in plant cell-wall polysaccharides by gasliquid chromatography. Carbohydr Res 5: 340-345

Bauer S, Vasu P, Persson S, Mort AJ, Somerville CR (2006) Development and application of a suite of polysaccharidedegrading enzymes for analyzing plant cell walls. Proc Natl Acad Sci USA 103: 11417-11422

Biswal AK, Soeno K, Gandla ML, Immerzeel P, Pattathil S, Lucenius J, Serimaa R, Hahn MG, Moritz T, Jönsson LJ, et al. (2014) Aspen pectate lyase PtxtPL1-27 mobilizes matrix polysaccharides from woody tissues and improves saccharification yield. Biotechnol Biofuels 7: 11

Blakeney AB, Harris PJ, Henry RJ, Stone BA (1983) A simple and rapid preparation of alditol acetates for monosaccharide analysis. Carbohydr Res 113: 291-299

Brown DM, Zhang Z, Stephens E, Dupree P, Turner SR (2009) Characterization of IRX10 and IRX10-like reveals an essential role in glucuronoxylan biosynthesis in Arabidopsis. Plant $J$ 57: $732-746$

Carpita NC, Gibeaut DM (1993) Structural models of primary cell walls in flowering plants: consistency of molecular structure with the physical properties of the walls during growth. Plant J 3: 1-30

Chong SL, Koutaniemi S, Virkki L, Pynnönen H, Tuomainen P, Tenkanen M (2013) Quantitation of 4-O-methylglucuronic acid from plant cell walls. Carbohydr Polym 91: 626-630

De Ruiter GA, Schols HA, Voragen AG, Rombouts FM (1992) 
Carbohydrate analysis of water-soluble uronic acid-containing polysaccharides with high-performance anion-exchange chromatography using methanolysis combined with TFA hydrolysis is superior to four other methods. Anal Biochem 207: 176-185

Doco T, O'Neill MA, Pellerin P (2001) Determination of the neutral and acidic glycosyl-residue compositions of plant polysaccharides by GC-EI-MS analysis of the trimethylsilyl methyl glycoside derivatives. Carbohydr Polym 46: 249-259

Eudes A, George A, Mukerjee P, Kim JS, Pollet B, Benke PI, Yang F, Mitra P, Sun L, Cetinkol OP, et al. (2012) Biosynthesis and incorporation of side-chain-truncated lignin monomers to reduce lignin polymerization and enhance saccharification. Plant Biotechnol J 10: 609-620

Guadalupe Z, Martinez-Pinilla O, Garrido A, Carrillo JD, Ayestaran B (2012) Quantitative determination of wine polysaccharides by gas chromatography-mass spectrometry (GC-MS) and size exclusion chromatography (SEC). Food Chem 131: 367-374

Hiei Y, Ohta S, Komari T, Kumashiro T (1994) Efficient transformation of rice (Oryza sativa L.) mediated by Agrobacterium and sequence analysis of the boundaries of the T-DNA. Plant J 6: 271-282

Hoebler C, Barry JL, David A, Delort-Laval J (1989) Rapid acid hydrolysis of plant cell wall polysaccharides and simplified quantitative determination of their neutral monosaccharides by gas-liquid chromatography. J Agric Food Chem 37: 360-367

Hongo S, Sato K, Yokoyama R, Nishitani K (2012) Demethylesterification of the primary wall by PECTIN METHYLESTERASE35 provides mechanical support to the Arabidopsis stem. Plant Cell 24: 2624-2634

Ishii T, Konishi T, Yamasaki T, Enomoto A, Yoshida M, Maeda I, Shimizu K (2010) NMR characterization of acidic xylooligosaccharides containing two methylglucuronic acid residues from Japanese cedar and Hinoki cypress. Carbohydr Polym 81: 964-968

Iwase A, Hideno A, Watanabe K, Mitsuda N, Ohme-Takagi M (2009) A chimeric NST repressor has the potential to improve glucose productivity from plant cell walls. J Biotechnol 142: 279-284

Jensen JK, Johnson NR, Wilkerson CG (2014) Arabidopsis thaliana IRX10 and two related proteins from psyllium and Physcomitrella patens are xylan xylosyltransferases. Plant $J$ 80: 207-215

Jones TM, Albersheim P (1972) A gas chromatographic method for the determination of aldose and uronic Acid constituents of plant cell wall polysaccharides. Plant Physiol 49: 926-936

Kumagai Y, Usuki H, Yamamoto Y, Yamasato A, Mukaihara T, Hatanaka T (2012) Preparation of hemicellulolic oligosaccharides from Chamaecyparis obtuse (hinoki) slurry using commercial enzymes. Front Chem Sci Eng 6: 224-231

Kuroyama H, Tsutsui N, Hashimoto Y, Tsumuraya Y (2001) Purification and characterization of a beta-glucuronidase from Aspergillus niger. Carbohydr Res 333: 27-39

Kwon H, Kim J (1993) Determination of monosaccharides in glycoproteins by reverse-phase high-performance liquid chromatography. Anal Biochem 215: 243-252

Lam TBT, Iiyama K (2000) Characteristics of senescent straw cell walls of dwarf, semidwarf, and normal strains of rice (Oryza sativa) plants. J Wood Sci 46: 376-380

Lee C, Teng Q, Huang W, Zhong R, Ye ZH (2009) Downregulation of PoGT47C expression in poplar results in a reduced glucuronoxylan content and an increased wood digestibility by cellulose. Plant Cell Physiol 50: 1075-1089

Lee C, Teng Q, Zhong R, Ye ZH (2011a) Molecular dissection of xylan biosynthesis during wood formation in poplar. Mol Plant 4: 730-747

Lee C, Teng Q, Zhong R, Ye ZH (2011b) The four Arabidopsis reduced wall acetylation genes are expressed in secondary wallcontaining cells and required for the acetylation of xylan. Plant Cell Physiol 52: 1289-1301

Lee C, Teng Q, Zhong R, Yuan Y, Haghighat M, Ye ZH (2012) Three Arabidopsis DUF579 domain-Containing GXM proteins are methyltransferases catalyzing 4-O-methylation of glucuronic acid on xylan. Plant Cell Physiol 53: 1934-1949

Leplé JC, Dauwe R, Morreel K, Storme V, Lapierre C, Pollet B, Naumann A, Kang KY, Kim H, Ruel K, et al. (2007) Downregulation of cinnamoyl-coenzyme A reductase in poplar: multiple-level phenotyping reveals effects on cell wall polymer metabolism and structure. Plant Cell 19: 3669-3691

Li Y, Qian Q, Zhou Y, Yan M, Sun L, Zhang M, Fu Z, Wang Y, Han B, Pang X, et al. (2003) BRITTLE CULM1, which encodes a COBRA-like protein, affects the mechanical properties of rice plants. Plant Cell 15: 2020-2031

Li M, Xiong G, Li R, Cui J, Tang D, Zhang B, Pauly M, Cheng Z, Zhou Y (2009) Rice cellulose synthase-like D4 is essential for normal cell-wall biosynthesis and plant growth. Plant $J 60$ : 1055-1069

Matsuura F, Imaoka A (1988) Chromatographic separation of asparagine-linked oligosaccharides labeled with an ultravioletabsorbing compound, $p$-aminobenzoic acid ethyl ester. Glycoconj J 5: 13-26

McNeil M, Darvill AG, Aman P, Franzén LE, Albersheim P (1982) Structural analysis of complex carbohydrates using highperformance liquid chromatography, gas chromatography, and mass spectrometry. Method Enzymol 83: 3-45

Nagel A, Sirisakulwat S, Carle R, Neidhart S (2014) An acetatehydroxide gradient for the quantitation of the neutral sugar and uronic acid profile of pectins by HPAEC-PAD without postcolumn pH adjustment. J Agric Food Chem 62: 2037-2048

Nakamura K, Tsumuraya Y, Hashimoto Y, Yamamoto S (1984) Arabinogalactan-proteins reacting with eel anti-H agglutinin from leaves of cruciferous plants. Agric Biol Chem 48: 753-760

Persson S, Caffall KH, Freshour G, Hilley MT, Bauer S, Poindexter P, Hahn MG, Mohnen D, Somerville C (2007) The Arabidopsis irregular xylem 8 mutant is deficient in glucuronoxylan and homogalacturonan, which are essential for secondary cell wall integrity. Plant Cell 19: 237-255

Pettolino FA, Walsh C, Fincher GB, Bacic A (2012) Determining the polysaccharide composition of plant cell walls. Nat Protoc 7: 1590-1607

Sakamoto S, Mitsuda N (2014) Reconstitution of a secondary cell wall in a secondary cell wall-deficient Arabidopsis mutant. Plant Cell Physiol, in press

Sannigrahi P, Ragauskas AJ, Tuskan GA (2010) Poplar as a feedstock for biofuels: A review of compositional characteristics. Biofuel Bioprod Biorefin 4: 209-226

Shallom D, Shoham Y (2003) Microbial hemicellulases. Curr Opin Microbiol 6: 219-228

Sluiter A, Hames B, Ruiz R, Scarlata C, Sluiter J, Templeton D, Crocker D (2008) Determination of structural carbohydrates and lignin in biomass, Laboratory analytical procedure (LAP). National Renewable Energy Laboratory Technical Report NREL/ TP-510-42618 
Smith BG, Harris PJ (1999) The polysaccharide composition of Poales cell walls: Poaceae cell walls are not unique. Biochem Syst Ecol 27: 33-53

Somerville C (2003) Cellulose synthesis in higher plants. Annu Rev Cell Dev Biol 22: 53-78

Swartz ME (2005) UPLC ${ }^{\mathrm{TM}}$ : an introduction and review. J Liq Chromatogr 28: 1253-1263

Takemoto H, Hase S, Ikenaka T (1985) Microquantitative analysis of neutral and amino sugars as fluorescent pyridylamino derivatives by high-performance liquid chromatography. Anal Biochem 145: 245-250

Urbanowicz BR, Peña MJ, Ratnaparkhe S, Avci U, Backe J, Steet HF, Foston M, Li H, O'Neill MA, Ragauskas AJ, et al. (2012) 4-Omethylation of glucuronic acid in Arabidopsis glucuronoxylan is catalyzed by a domain of unknown function family 579 protein. Proc Natl Acad Sci USA 109: 14253-14258

Vega-Sánchez ME, Verhertbruggen Y, Christensen U, Chen X, Sharma V, Varanasi P, Jobling SA, Talbot M, White RG, Joo M, et al. (2012) Loss of cellulose synthase-Like F6 function affects mixed-linkage glucan deposition, cell wall mechanical properties, and defense responses in vegetative tissues of rice. Plant Physiol 159: 56-69

Vignon MR, Gey C (1998) Isolation, ${ }^{1} \mathrm{H}$ and ${ }^{13} \mathrm{C}$ NMR studies of (4-O-methyl-D-glucurono)-D-xylans from luffa fruit fibres, jute bast fibres and mucilage of quince tree seeds. Carbohydr Res 307: $107-111$

Willför S, Sundberg A, Pranovich A, Holmbom B (2005) Polysaccharides in some industrially important hardwood species. Wood Sci Technol 39: 601-617
Yasuno S, Murata T, Kokubo K, Yamaguchi T, Kamei M (1997) Two-mode analysis by high-performance liquid chromatography of $p$-aminobenzoic ethyl ester-derivatized monosaccharides. Biosci Biotechnol Biochem 61: 1944-1946

Yasuno S, Kokubo K, Kamei M (1999) New method for determining the sugar composition of glycoproteins, glycolipids, and oligosaccharides by high-performance liquid chromatography. Biosci Biotechnol Biochem 63: 1353-1359

Yates EA, Valdor JF, Haslam SM, Morris HR, Dell A, Mackie W, Knox JP (1996) Characterization of carbohydrate structural features recognized by anti-arabinogalactan-protein monoclonal antibodies. Glycobiology 6: 131-139

Zablackis E, Huang J, Müller B, Darvill AG, Albersheim P (1995) Characterization of the cell-wall polysaccharides of Arabidopsis thaliana leaves. Plant Physiol 107: 1129-1138

Zhang SJ, Song XQ, Yu BS, Zhang BC, Sun CQ, Knox JP, Zhou YH (2012) Identification of quantitative trait loci affecting hemicellulose characteristics based on cell wall composition in a wild and cultivated rice species. Mol Plant 5: 162-175

Zhong R, Peña MJ, Zhou GK, Nairn CJ, Wood-Jones A, Richardson EA, Morrison WH 3rd, Darvill AG, York WS, Ye ZH (2005) Arabidopsis fragile fiber8, which encodes a putative glucuronyltransferase, is essential for normal secondary wall synthesis. Plant Cell 17: 3390-3408

Zhou Y, Li S, Qian Q, Zeng D, Zhang M, Guo L, Liu X, Zhang B, Deng L, Liu X, et al. (2009) BC10, a DUF266-containing and golgi-located type II membrane protein, is required for cell-wall biosynthesis in rice (Oryza sativa L.). Plant J 57: 446-462 